\title{
Ritmo na língua e na música: o elo possível
}

\author{
Beatriz Raposo de Medeiros* \\ Universidade do Estado de São Paulo
}

\section{Resumo:}

Partindo de uma discussão sobre o que é língua e linguagem, procura-se aclarar como se deve empregar o termo "linguagem" em relação à música. Em seguida, propõe-se uma compreensão de música e língua como sistemas dinâmicos. Uma vez compreendidos como sistemas que envolvem movimento, por isso passíveis de receber modelamentos envolvendo a ideia de osciladores, os sistemas linguístico e musical se irmanam crucialmente através do ritmo. O ritmo é visto como o fenômeno organizador do movimento humano. Ao final, propõe-se aprofundar os estudos sobre cognição musical entendendo-se a música como movimento e o ritmo como viabilizador desse movimento.

Palavras-chave: língua; música; ritmo e sistemas dinâmicos.

\footnotetext{
* Beatriz Raposo de Medeiros, é professora doutora do Departamento de Linguística da Universidade de São Paulo. Seu trabalho de pesquisa é voltado, tanto para a linguística como para a música, discutindo a questão da integração entre a fonética e fonologia e da relação fala/canto a partir da canção. Em pós-doutorado na Université de Provence, desenvolveu pesquisa no Laboratoire Parole Langage (LPL) na França, sobre a nasalidade vocálica do português brasileiro. Atua na pós-graduação do Departamento de Línguas Clássicas e Vernáculas da Universidade de São Paulo, orientando pesquisas em torno da prosódia, na fala e na canção.
} 
Todo o material da arte repousa sobre uma abstração: a escultura, p.ex., desdenha o movimento e a cor; a pintura desdenha a $3^{a}$ dimensão $e$ movimento, portanto; a música desdenha tudo quanto não seja o som; a poesia baseia-se na palavra, que é a abstração suprema e por essência, porque não conserva nada do mundo exterior. porque o som - acessório da palavra - não tem valor senão associado - por impercebida que seja essa associação.

(Fernando Pessoa, in Obras em Prosa)

\section{Introdução}

O signo é o elemento imprescindível da linguagem. Para se haver uma linguagem é preciso haver um signo. Ferdinand de Saussure, o fundador da Linguística Moderna estabelece a natureza do signo linguístico, como arbitrário e integrante de significante e significado. Marca assim, profundamente, o nosso entendimento sobre a linguagem. Uma linha é traçada entre língua e linguagem pelo mestre de Genebra, a qual nos auxilia a pensar melhor sobre as diferentes linguagens, sua natureza e de qual ciência devem ser matéria. As reflexões sobre linguagem expostas a seguir (Mota Maia, 1991; Borges 2005; Schroeder, 2006) são cuidadosas em tentar traçar também as diferenças entre diferentes linguagens e aqui receberão alguma discussão.

A partir dessa discussão, convidamos o leitor ou a leitora a considerar a Linguística como a disciplina que, ao delimitar seu objeto de estudo e estabelecer os níveis de análise - fonética, fonologia, morfologia, sintaxe -, determina os rumos nos estudos das línguas naturais. Desde a dicotomia saussureana (língua e fala), passando pelos constituintes sintáticos do gerativismo, até achados mais recentes sobre capacidades linguísticas emergentes, definir a natureza da unidade a ser estudada é crucial e fundamental. ${ }^{1}$ Não faremos aqui uma história da

\footnotetext{
${ }^{1}$ O gerativismo tem como um texto seminal o Syntatic Structures de Noam Chomsky, datado de 1957. O emergentismo é defendido por cientistas conexionistas, como Mac Whinney (2002).
} 
Linguística, mas apontaremos, quando necessário, alguns marcos importantes da ciência da linguagem.

Uma vez estabelecidas as diferenças entre língua e linguagem, na próxima seção (2), falaremos de um modelo teórico afeito à dinâmica no interior da Linguística e exporemos porque ele torna mais instigante tratar o ritmo como moeda comum entre as disciplinas: linguística e música. Pensar a língua como algo dinâmico, ou seja, constituído de movimento, já é desafiador, dado que os modelos teóricos da Linguística são mentalistas - como o gerativismo, o mais conhecido. É ainda mais desafiador propor o ritmo como um elo comum entre a língua e a música, no sentido de que não há ritmos definidos a partir de uma determinada atividade humana. O que há é o ritmo, fenômeno presente nos movimentos. Assim, trata-se de aclarar conceitos entre duas disciplinas e intercambiar noções, sempre que necessário.

\section{Língua e linguagem}

Do que nos ensinou Saussure, é importante destacar o seguinte:

Mas o que é língua? Para nós ela não se confunde com a linguagem; é somente uma parte determinada, essencial dela, indubitavelmente. É, ao mesmo tempo, um produto social da faculdade da linguagem e um conjunto de convenções necessárias, adotadas pelo corpo social para permitir o exercício dessa faculdade nos indivíduos. Tomada em seu todo, a linguagem é multiforme e heteróclita; a cavaleiro de diferentes domínios, ao mesmo tempo física, fisiológica e psíquica, ela pertence além disso ao domínio individual e ao domínio social; não se deixa classificar em nenhuma categoria de fatos humanos, pois não se sabe como inferir sua unidade. (p. 17).

Dois aspectos sobre as diferenças devem ser assimilados desta passagem: um é de que a língua natural é parte da linguagem, ou ainda, dos "fatos da linguagem", como diz Saussure. O outro aspecto diz respeito à linguagem e sua unidade: perguntar qual seria a unidade da linguagem é perguntar sobre um signo comum a todas as linguagens. Isso, segundo Saussure, não é inferível. Ou 
seja, não existe um signo comum da linguagem, mas signos de linguagens. Não vamos desenvolver esse aspecto agora, pois seria aprofundar as reflexões sobre o signo, o que não é a proposta deste trabalho. No entanto, vale a pena deixar aqui a questão sobre qual seria a unidade musical. Há alguma teoria musical preocupada em delimitar o objeto de estudo da Música e sua(s) unidade(s), como a Linguística o fez?

Enquanto aguardamos possíveis respostas a tais perguntas - pois até onde se sabe não há uma unidade musical estabelecida como paradigma científico tomemos como base para toda e qualquer discussão sobre linguagem, a explicação saussureana sobre língua e linguagem. A partir dele, como veremos a seguir, outras reflexões sobre língua e linguagem nos ajudam, com efeito, a separar melhor os conceitos para que não haja mais confusão. Neste sentido, e falando agora do lugar da música, somos devedores da Linguística.

Ainda um terceiro aspecto saussureano da linguagem é preciso apreender: o de que o estudo da linguagem deve se dar no âmbito da Semiologia, ciência que estuda os signos de modo geral, e em cujo domínio está a Linguística. Saussure adianta-se logo a esclarecer que a Semiologia não existe, está por ser fundada. Tal fundação, na verdade nunca aconteceu, mas houve outra: a da Semiótica, em um longo período entre o final do século XIX e meados do século XX, no qual autores importantes, entre outros, são Charles Peirce, Julius Greimas e Humberto Eco.

Passemos agora a observar o emprego do termo linguagem, tanto relativo à língua natural, como à linguagem. Ao levar o leitor a refletir sobre o que é a linguagem, em o Reino da Fala, Mota Maia (1991) sustenta duas teses possíveis: uma, em que o significado de linguagem seja mais abrangente e outra, em que seja estreito. O sentido lato ou abrangente seria o da linguagem como comunicação, independente de sua estrutura e, nesse sentido, cabe estudá-la no âmbito da Semiótica. Um exemplo de linguagem como comunicação sem auxílio da língua natural, pode ser a linguagem dos costumes ligados ao vestuário, como 
vestir roupas pretas para sinalizar luto. ${ }^{2}$ No sentido mais estreito, a linguagem é estrutura cuja natureza é a da segmentabilidade e combinabilidade. Estamos falando aqui da dupla articulação da linguagem, em que segmentos da ordem da palavra são segmentáveis em morfemas (primeira articulação) e morfemas podem ser segmentados em fonemas, unidades menores e destituídas de sentido (segunda articulação) (Martinet, 1978). Ou ainda, pode-se falar da duality of patterning (Hockett, 1960 apud Goldtein et al. 2006), conceito em que se distinguem os diferentes padrões de combinação entre unidades cognitivas: a fonologia é responsável por nossa capacidade de combinar unidades pequenas sem significado para formar palavras; e a sintaxe, em organizar hierarquicamente as palavras em frases.

Em outras palavras, a dupla articulação da linguagem provém da capacidade humana de desenvolver uma estrutura em que padrões menores se combinam com maiores, para significar. Tais combinações não são aleatórias e seguem regras específicas, fato para o qual atentou Shroeder (2006) ao levantar questões sobre a sintaxe musical e a sintaxe linguística, comparando-as. A autora diz:

Ao aprofundarmos a comparação, entretanto, começamos a perceber que não apenas os modos de cómbinação musicais e linguísticos não são exatamente os mesmos, como não são também as mesmas as características das unidades básicas. (p. 107).

As diferenças a que Schroeder faz referência são fundamentais para entendermos as fronteiras entre as duas linguagens: a musical e a língua natural. É preciso estar claro, ao longo desta exposição, que o termo “linguagem” é compreendido a partir do limite estabelecido por Saussure entre língua e linguagem. Cabe aqui acrescentar a ideia de que a analogia entre os níveis linguísticos (o fonético-fonológico, por exemplo) e possíveis níveis musicais só é plausível se os empregarmos como metáfora, partindo-se do fato de que as unidades menores das línguas naturais (building materials) não carregam

\footnotetext{
${ }^{2}$ É claro que podemos elencar outros exemplos de linguagem, como por exemplo a linguagem gráfica dos sinais de trânsito. Saussure dá como exemplos de linguagem, os sistemas de signos dos ritos simbólicos e os sinais militares, entre outros.
} 
significado, acontecendo o mesmo com o material sonoro que constitui a música (Borges, 2005). No entanto, o mesmo autor atenta para o fato de que a música não alçaria ao padrão de combinação entre morfemas, pois não possui unidade equivalente a esse, ou nem mesmo à palavra, o que torna impossível falar de semântica musical. É crucial notar que, ao fazer a pergunta Is music a language?, Borges (2005) está se referindo à linguagem no seu sentido estreito, como vimos em Mota Maia (1991), e por tal razão, defende que não é possível haver uma semântica musical, ou se fazer uma análise semântica musical, já que não é possível determinar a referência de um enunciado musical a coisas do mundo ou de um mundo possível, e sequer verificar-lhe a verdade.

Corremos o risco de pensar que a linguística estabeleceu muito bem sua matéria e sua unidade de análise. Isso até pode ser dito no âmbito do estruturalismo, mas no desenvolvimento da ciência linguística, outras visões teóricas sobre a língua natural têm origem e, às vezes, apontam em sentidos opostos. No entanto, é plausível dizer que as ideias saussureanas aclararam o objeto a ser estudado e estabeleceram-se como referências para se falar de signo e linguagem. Não fosse assim, os estudos de estrutura musical não se serviriam das metáforas de que falamos há pouco.

No sentido contrário, a Linguística é devedora da Música. O grande comprometimento com a escrita, desde o tempo do desenvolvimento da gramática grega (há cerca de 2,5 mil anos) até a linguística moderna - esta, ainda hoje, fortemente influenciada pela visão alfabética dos sons da fala - distanciou os linguistas do som (Medeiros, 2006).

Falar de sentido da música, sobretudo quando se fala de uma semântica musical, ou ainda de significado musical (Sloboda, 2008; Nogueira, 2009; Oliveira et al., 2008) é plausível, desde que não se queira empregar os termos significado e semântica, assim como são usados para o estudo das línguas naturais. Sigamos o que sugeriu Saussure: a língua faz parte da linguagem. As linguagens se estruturam de modos diferentes. E se gostamos de negociar metáforas ou empregar termos comuns entre as duas áreas do saber, Linguística e Música, é porque o material sonoro de ambas oferece essa possibilidade. 


\section{Ritmo na língua e ritmo na música}

Todos temos a intuição de que existem batidas mais ou menos regulares na fala. Seja porque, corriqueiramente, repetimos frases curtas e descobrimos aí uma pulsação, seja porque recitamos parlendas para nossas crianças, seja porque aceitamos muito melhor uma poesia ritmada do que um texto em prosa ritmado. Enfim, no fluxo contínuo da fala, espontânea ou preparada, é possível perceber ritmo, ainda que em diferentes graus, pois a coordenação temporal da fala parece não ser tão estrita. Mas em que aspecto da matéria fônica estaria o ritmo?

O ritmo linguístico tem sido estudado como pulsações em intervalos regulares de tempo (Pike, 1945; Lehiste, 1977); como batidas alternando-se em forte e fraco, hierarquizadas em níveis maiores - por exemplo, da sílaba à frase (Liberman e Prince, 1977; Hayes, 1995); como passível de tipificar as línguas, dividindo-as como línguas de ritmo acentual, de um lado, e línguas de ritmo silábico, de outro (Pike, 1945; Dauer, 1983) e ainda, como referente à modulação de amplitude do sinal acústico da fala (Ramus e Mehler, 1999).

Ao se estudar ritmo musical, desvendar seu lugar no material sonoro da música não parece ser problemático. O ritmo não só se revela neste material, como é parte constituinte dele. ${ }^{3}$ O ritmo na fala também é constitutivo desta, mas é menos crucial: uma prova disso é que não existem intervalos de tempo regularmente espaçados, a não ser que esses intervalos emerjam como batidas suscitadas pelo tipo de fala realizada, como mencionado anteriormente: parlendas, poemas etc. Na fala corrente, com períodos longos, não se detectam batidas regulares (Cummins, 2009; Port, Cummins e Gasser, 1995). Já na música, a organização rítmica é fundamental, tanto que o problema não é apontar "onde está o ritmo", mas revelar seu aspecto psicológico e cognitivo. Em "Ritmo e altura na cognição musical”, Krumhansl (2006) nos dá um panorama do ritmo que passamos a resumir a seguir e que vem ao encontro das ideias centrais deste

\footnotetext{
3 Podemos ter peças musicais "desprovidas" de ritmo, constituídas de notas longas, cujas alturas se fundem em fluxo contínuo. Mas exatamente o que marcaria a particularidade de uma tal peça é o fato de "não ter ritmo"; ou seja, a referência à ausência de algo dá a dimensão de quanto este algo é importante.
} 
trabalho. Nossa capacidade cognitiva temporal lida com uma duração mínima de um evento sonoro (em média 600 milissegundos), e com o agrupamento binário (dois ou quatro) de eventos sonoros que se repetem como que em fluxo contínuo. Ainda, dos estudos de ritmo no âmbito da pesquisa musical, sabe-se que a percepção de categorias rítmicas envolvendo padrões simples (1:2) é verificada tanto junto a não-músicos como músicos, estes últimos se saindo melhor quando tem de repetir padrões complexos (1:3 ou 1:4). Neste sentido, as hierarquias rítmicas encontradas na música ocidental que correspondem a compassos tais como 2/4 e 4/4 (correspondentes a 1:2 e 1:1, ou seja, padrões simples) com acentos iniciais, são motivadas por uma percepção e produção de ritmo naturais ao ser humano. A capacidade rítmica não estaria a serviço de determinadas atividades humanas (como fala e música, por exemplo), mas presente em todas as atividades humanas envolvendo movimento. Faz-se, então, inevitavelmente, uma ponte entre a capacidade rítmica e o controle motor.

Ao se falar em movimento, podemos nos referir, então, a visões sobre a organização temporal linguística diferentes do mainstream, esse último, representado nos trabalhos sobre ritmo na língua citados acima. Uma visão que possibilita integrar ritmo e movimento na fala é a visão dinâmica, ${ }^{4}$ representada na Linguística pela Fonologia Articulatória ou Fonologia Gestual (FG), como tem sido chamada recentemente por seus autores e da qual traçaremos alguns princípios gerais na próxima seção (4).

A ideia da fala como sistema dinâmico é fundamental para Fred Cummins, que propõe que o movimento (a dança, por exemplo) em sincronia com outro movimento, viabiliza-se através do ritmo. Ritmo é um fenômeno ubíquo e central a várias atividades humanas e seu entendimento deve ser tal que possamos conceituá-lo como moeda comum entre as diferentes áreas da ciência (Cummins, 2009).

Excetuando-se a visão dinâmica, as visões de ritmo da fala expostas acima são consideradas insuficientes para Cummins, de quem adotamos a concepção de

\footnotetext{
${ }^{4}$ Ver Browman \& Goldstein, 1995, em Port e Van Gelder, 1995.
} 
ritmo e o qual passamos a tratar como elo comum entre a língua e a música. Defendemos que tal tratamento só é possível se abandonarmos as ideias de ritmo linguisticas nascidas no interior da visão fonológica tradicional, a qual não leva em consideração o tempo intrínseco das unidades fonológicas, e tão pouco as vê como movimento.

\section{0 movimento na fala e o movimento na música}

Os princípios da Fonologia Gestual são de que as unidades fonológicas são ao mesmo tempo unidades de ação (movimento articulatório) e unidades de informação (unidades de sentido, porque distintivas). Ora, isso já representa um embate no interior da Linguística, pois, tradicionalmente, o que é do nível físico, não interessa à fonologia, e se a unidade proposta é de ação/informação ao mesmo tempo, em princípio, as teorias linguísticas não deveriam aceitar. No entanto, para aqueles estudiosos que aderem à visão dinâmica da cognição, tentando, a partir daí, explicar a linguagem, não há problema em reconhecer o gesto articulatório - e não mais o abstrato fonema - como unidade da fonologia.

De forma bastante abrangente, a partir de um modelo dinâmico da fala, podemos entender o seguinte: os gestos articulatórios são padrões de movimento articulatório que se coordenam entre si para formar uma unidade lexical. Podemos entender gestos articulatórios como as vogais e consoantes que se combinam para formar palavras. Sabemos que a resultante acústica de gestos vocálicos é um som da fala melodioso e contínuo, ao passo que a consoante é ruidosa e muitas vezes interrompida. Isso se deve ao fato de que a vogal busca um formato do trato vocal, em que a ressonância seja maximizada, e o ar possa passar livremente. Esse já não é o caso das consoantes, cuja articulação privilegia o fechamento total ou crítico do trato vocal. O modelo fonológico dinâmico propõe explicar como vogais e consoantes se combinam, levando em conta aspectos temporais e espaciais de gestos que, como vimos, têm suas particularidades articulatórias. 
O modelo utilizado pela fonologia gestual para explicar como se coordenam os gestos articulatórios é o modelo de dinâmica de tarefa ${ }^{5}$ que, por sua grande complexidade, não vai ser exposto aqui - a não ser pela ideia de osciladores acoplados. Basta entender que tal modelo conseguiu revelar, integrando o físico e o cognitivo, padrões de coordenação dos articuladores responsáveis pela produção de fala, a qual estava relegada a ser entendida apenas como traços corporais concretos, os quais não teriam nenhuma ligação com a capacidade simbólica.

Cumpre agora explicar a ideia de osciladores acoplados, o que não fica muito difícil entre músicos, uma vez que o pensamento musical lida sempre com eventos sonoros no tempo e com solucionar a integração de tais eventos. Um exemplo de osciladores acoplados seria o de uma partitura para piano, com suas pautas, a superior e a inferior. Cada uma dessas pautas representa um conjunto de eventos temporais e de alturas que devem ser integrados, em fase ou antifase, mas com interdependência temporal, por isso acoplados. Imaginemos que um nível de coordenação da fala, o intergestual, precise dar conta de vogais e consoantes como osciladores acoplados. Embora nossa tradição alfabética veja as combinações entre esses sons da fala como justapostas, na verdade, elas se sobrepõem. Um exemplo disso é que ao falar a palavra $t u$, arredondamos os lábios já na produção da consoante /t/, embora esta não seja especificada para o traço de arredondamento. Assim, sabe-se que para o gesto vocálico, o arredondamento dos lábios no caso do /u/, já está ativado durante o gesto consonantal, o /t/, ao se pronunciar a palavra tu. Isso indica que há um contínuo entre gestos articulatórios e que podem então ser vistos, grosso modo, como eventos no tempo que têm de se coordenar. Ou, ainda, no plano do modelamento do movimento, como osciladores que podem estar em fase ou fora de fase.

Embora esta ideia de osciladores acoplados não nos pareça muito intuitiva no nível de ordens mais baixas, como as vogais e consoantes, ela poderá soar mais plausível no nível da frase, por exemplo. Trabalhos mais recentes do

\footnotetext{
${ }^{5}$ Para detalhes, ver Elliot Saltzman e K. G. Munhall, A dynamical approach to gestural patterning in speech production, Ecological Psychology 1, p. 333-382, 1989.
} 
modelo da FG têm tratado disso (Saltzman et al, 2008). Para além da coordenação intergestual, envolvendo o gesto e a sílaba, os autores propõem gestos de modulação temporal (p-gestos, ou gestos-p) como conjunto de osciladores de períodos rítmicos, para dar conta dos níveis prosódicos mais altos, como a frase. Poderíamos comparar este modelo chamado de conjunto de osciladores multinível a um quarteto de cordas em que os instrumentos mais graves fossem responsáveis pelas frases (períodos mais longos), e os mais agudos trabalhariam o ritmo e as alturas nas sílabas (em períodos mais curtos), que, por sua vez, deveriam estar aninhados nos períodos mais longos.

Em termos bem gerais, o movimento na fala é um movimento em busca da organização da matéria fônica e pode ser entendido como uma entidade mais abstrata, como o gesto articulatório, realizado de maneira orquestrada intergestualmente, em sílabas, pés e frases.

A tarefa agora seria deslindar o que é movimento na música. No entanto, até onde se sabe, a não ser por um trabalho de Michael (2006), não se tem um modelo teórico voltado para explicar música através de uma ótica dinâmica. Michael (2006) propõe um modelo dinâmico de oscilador não-linear para a siringe da ave canora, a partir do qual é possível simular o canto do pássaro, alterando, por exemplo, os parâmetros da equação que dizem respeito à pressão aérea bronquial e à tensão das lábias. A siringe, laringe inferior das aves, deve ser considerada como um atuador (actuator): o órgão responsável pela produção do som e cuja motricidade é controlada por vias neurais, pelo menos para altura $\left(F_{0}\right)$ e volume. Assim, ao excitar, através da equação que serve de base para a simulação do canto da ave, o valor ou parâmetro que representa a rigidez das lábias, haverá aumento de frequência fundamental. Se concordarmos que tal modelo dinâmico desvenda a organização do movimento do canto do pássaro, cujo cérebro desempenha papel de controlar, adquirir e reproduzir o material sonoro, podemos contemplar a ideia de que o movimento musical em seres humanos nasce da capacidade de cantarmos.

Então, vejamos como isso se dá, a custo de um pouco de especulação. A música está no ar e está dentro de nós. Em princípio, todo material sonoro do 
mundo pode ser convertido em música, o que tem sido melhor aceito apenas mais recentemente na história da música ocidental. Podemos lidar com a ideia de que o que a capacidade musical humana sempre fez, foi organizar os eventos sonoros em música, de forma cada vez mais elaborada, criando ordem a partir do caos e, assim, estabelecendo formas mais ou menos rígidas, ou mais ou menos definidas de fazer música, a que chamamos de composição musical. A música contemporânea agiria como um processo de desmontar o mecanismo de algo dado, ou já pronto, ou seja, de formas musicais estabelecidas tradicionalmente. Seja seguindo padrões já estabelecidos de se compor música, seja fazendo música que explora novas sonoridades e diferentes elaborações de altura e ritmo, a questão é: o que está por trás do fazer musical? Ou, em outras palavras, o que é saber fazer música?

Neste momento, podemos lançar a ideia de que aprendemos ou adquirimos uma habilidade a partir da corporificação de eventos do mundo. Podemos, assim, dizer que nossa capacidade de elaborar sons periódicos ou quase periódicos e sons percussivos - tudo ritmicamente integrado - tem sua origem na habilidade de emitir a voz e controlar $F_{0}$ e intensidade, além da duração do evento vocal. Este "cantar" corporificou a música e nos permitiu compreendê-la como movimento, já que ajustando determinados articuladores como a laringe - e o fluxo de ar, podia-se produzir os sons desejados. Seria possível então falar do canto como sistema de afinação de diferentes alturas e durações, analogamente ao que se falou do canto da ave, portanto, como passível de ser compreendido e modelado como um sistema dinâmico. Aí estaria o movimento da música. No entanto, o canto é apenas o movimento inicial; fazer música não passa obrigatoriamente pelo gesto canoro, mas "fazer" fala, passa necessariamente pelo gesto articulatório. O caminho que vai da concepção/saber musical ao resultado acústico parece-nos ser aquele em que os processos mentais puderam contar com uma base perceptiva e corpórea - ou ambas ao mesmo tempo - do que é música. Ou seja, ao se fazer música, está-se concretizando um movimento aparentemente apenas mental, mas que, em dado momento da experiência humana, foi corporificado. 
Retomando tudo o que foi dito até agora nesta seção: o movimento da fala está em gestos articulatórios e o movimento da música está, em primeira instância, no canto. A seguir, exporemos as ideias mais gerais de Cummins sobre ritmo (2003, 2009a, 2009b), e defenderemos, nelas baseados, que se há movimento, há que haver ritmo para organizá-lo.

\section{0 ritmo como elo entre fala e música}

Vimos que a opção por uma visão dinâmica da língua nos leva a definir o que é movimento da fala e a arriscar uma explicação análoga para movimento na música, aproximando as áreas do conhecimento responsáveis por explicar as capacidades linguística e musical.

Já, há mais de uma década, os trabalhos de Fred Cummins sobre o ritmo linguístico defendem que é preciso iluminar a busca sobre o que é ritmo a partir do conhecimento de outras áreas da ciência (Port, Cummins e Gasser, 1995; Port, Cummins e MacAuley, 1995). Neste sentido, a visão de Cummins sobre ritmo na fala se distancia das visões que querem dar conta do fenômeno a partir de conceitos simbólicos como "acento", "pé” ou "sílaba”. 6 A proposta de Cummins e colegas é bastante ousada, no sentido de propor, de certo modo, que a gramática incorpora o movimento:

We suspect that the grammar used by speakers incorporates an oscillatory system that generates rhythmic structures during speech production and also internally generates a similar perceptual rhythm when listening to speech. (Port, Cummins e Gasser, 1995, p. 7 do manuscrito).

Para provar a existência de um sistema que estrutura padrões rítmicos, tanto na produção como na percepção da fala de diferentes línguas, como o japonês e o inglês, por exemplo, Cummins et al. (1995) sugerem que tal sistema

\footnotetext{
${ }^{6}$ Tais conceitos são considerados simbólicos no âmbito de uma linguística simbólica, ou seja aquela em que o nível gramatical só opera com símbolos, para a qual, a produção de fala é algo físico e por isso excluída do que é mental.
} 
pode ser simulado através de osciladores adaptativos. Osciladores adaptativos aplicados para explicar a percepção da integração de eventos periódicos com batidas repetitivas foram desenvolvidos para dar conta, tanto de encontrar o metro numa sequência musical, como numa sequência de sons da fala (Large e Kolen, 1994; McAuley, 1995). Deixando de lado as questões mais complexas, detalhistas e técnicas de modelamentos, tal qual fizemos anteriormente em relação aos osciladores acoplados da FG, podemos descrever um oscilador adaptativo da seguinte maneira: trata-se de gerar uma senóide, onda simples e, a um dado momento, introduzir pulsos (input) que se sobrepõem a essa onda, restabelecendo seu início de forma abrupta. Aos poucos, a onda simples se adapta aos pulsos introduzidos, e recupera sua fase, em uma relação harmônica com esses pulsos. Quando estes cessam, a onda volta à sua forma de senóide original. Os pesquisadores sugerem que o padrão rítmico moraico do japonês ou padrão de pés do inglês (uma sílaba acentuada e outra não) podem ser convertidos em pulsos de osciladores adaptativos e, assim, concluem que o ritmo na fala deve ser tratado como se tratam outras estruturas periódicas no tempo.

Em termos da dinâmica cognitiva, Fred Cummins e seus colegas perseguem, inicialmente, uma visão de ritmo em que este é considerado como um mecanismo de coordenação do movimento. Propõem, então, que o ritmo linguístico não é um fenômeno diferente de ritmo em geral. A função do ritmo no corpo humano é a de regular a coordenação de grupos de músculos, e no caso da fala, os grupos de músculos ligados à sua articulação.

Em estudos mais recentes, Cummins $(2003,2009)$ propõe que sempre que houver uma estrutura de sinal específico integrando-se com outra, lançar-se-á mão do ritmo para tal integração. O ritmo, então, é visto como uma affordance para a integração (entrainment) ${ }^{7}$ do movimento (Cummins, 2009b). A palavra affordance pode ser traduzida como viabilização, e diz respeito à percepção e ação (Gibson, 1979 apud Cummins, 2009b) e a relação

${ }^{7}$ Há também a possibilidade de se traduzir entrainment por carreamento. 
que se estabelece entre um dado organismo - ou estrutura - com seu meio (Chemero, 2003 apud Cummins, 2009b).

Dois sistemas rítmicos, mas não estritamente periódicos, como é o caso da fala, podem revelar maior restrição temporal quando sincronizados. Os experimentos de fala sincronizada demonstram que dois falantes, ao ler um mesmo texto, em presença um do outro, reduzem as idiossincrasias temporais de suas falas, agindo como osciladores acoplados (Cummins, 2003, 2009a, 2009b). Inícios de frases e sílabas se ajustam entre os dois indivíduos na fala sincronizada, assim como as pausas passam a ter a mesma duração.

Em diferente proporção, na música também acontece o mesmo. Consideremos, assim como Cummins faz para a fala sincronizada, que dois indivíduos executando uma peça musical atuam como osciladores acoplados, no sentido de que tem de integrar (ou carrear) seus movimentos para que a peça soe como uma unidade. Na qualidade de osciladores acoplados, o pianista e o cantor, por exemplo, têm de buscar ajustar os ritmos de forma ainda mais precisa do que quando ensaiam suas partes separadamente. Aliás, essa é uma diferença entre solistas e músicos de grupo: aqueles primeiros, em geral, têm mais liberdade rítmica do que os últimos.

A sincronização da fala se dá por um conjunto de sinais físicos como amplitude, $F_{0}$ e presença da vogal (em oposição à presença do ruído). Quando apenas um desses sinais é modificado, não há comprometimento total da sincronia entre o falante e o modelo da fala que lhe é fornecido para a realização da fala sincronizada. Sendo assim, fica difícil revelar o quê, do sinal acústico, isoladamente, é a pista para o acoplamento. Isto ampara uma proposta de que o ritmo da fala não reside em sinais específicos, mas antes é uma estrutura temporal, presente na integração de movimentos em geral e que encontra um contínuo em outros movimentos da natureza (Cummins, 2009b).

Outros exemplos de entrainment (integração ou carreamento) são a relação entre corpos dançando e a música, a recitação de parlendas e o balançar do corpo e, ainda, o exemplo clássico de dois pêndulos acoplados. A visão dinâmica da fala e da música precisa explicar como se dá o movimento em um e 
outro sistema, a fim de explicitar a coordenação temporal dos gestos que as constituem. Tal coordenação é crucial para a distintividade fônica, no caso da língua, no caso da música, para a apreensão da estrutura musical pretendida.

\section{Conclusão}

A pergunta agora é: se ritmo é viabilização (affordance) para movimento, e se affordance é entendida aqui como a relação de agente - ambiente (Gibson, 1979 apud Oliveira e Rodrigues, 2006) em que lugar da relação entre o movimento musical (ou da fala) e o indivíduo está esse ritmo? A questão se coloca para que aclaremos da melhor forma possível aquilo que propomos neste trabalho: o ritmo como elo entre a música e a fala. Explicar o que é affordance gibsioniana, ou seja, explicá-la com base na psicologia da percepção visual, levanos a entender, por exemplo, a relação do indivíduo com uma superfície sobre a qual tem de executar um movimento qualquer. Perceber que a superfície é caminhável viabiliza a maneira pela qual os passos serão dados (Oliveira e Rodrigues, 2006). No entanto, o entendimento sobre como funciona a percepção

60 de ritmo como algo responsável pela organização de sistemas disparatados (Cummins, 2009b), tem de passar por um questionamento mais fino. Ainda não temos uma resposta para isso, mas arriscamos dizer que o ritmo deve ser entendido em suas bases fisiológicas e neurocognitivas.

Sabemos que a aptidão para perceber o ritmo e criar agrupamentos não pertence a um sistema diferente da produção de tais agrupamentos (Krumhansl, 2006). Assim, também há, no âmbito da linguística, argumentos em favor de que a percepção da fala dá conta das mesmas unidades de produção da fala. Por exemplo, não percebemos apenas sons distintivos, mas também a motricidade envolvida na produção desses sons. Se percebermos o sinal acústico e os movimentos articulatórios da fala, percebemos também como esses se organizam temporal e espacialmente, da mesma maneira que percebemos o movimento dos membros do corpo. Assim, podemos aderir à ideia de que o ritmo percebido na fala é o mesmo que organiza os movimentos corporais de um modo geral. 
Sugerimos, então, que a pesquisa em cognição musical aprofunde os seguintes aspectos:

- A música como movimento, buscando evidências com base em teorias que defendem a corporificação (MacWhinney, 2001, por exemplo) e visões dinâmicas da música, tomando como ponto de partida Large e Kolen (1994) e Michael (2006), por exemplo.

- O ritmo como o fenômeno viabilizador do movimento, buscando uma compreensão mais abrangente desse aspecto, como sua natureza no funcionamento do corpo humano, indo do fisiológico ao motor, até podermos aderir, se for o caso, ao ritmo com sua realidade neurocognitiva, em que oscilações neurais produzam pulsos a cada ciclo (Port, 2003).

Nossa aposta é a de que estes dois passos, ainda que largos, possam ser dados com tranquilidade no caminho da visão dinâmica, e venham a fornecer respostas esclarecedoras sobre o saber musical. Ainda que seja um aclaramento inicial, o gesto em direção a uma compreensão de música e língua como sistemas dinâmicos é um ganho, pois propicia o entendimento de uma "mente menos simbólica" e de um "corpo menos físico", o funcionamento de ambos concorrendo para nossas capacidades de ação e abstração.

\section{Referências}

MOTA MAIA, E. No reino da fala: a linguagem e seus sons. São Paulo: Ática, 1991.

BORGES, J. L. Is music a language? Anais do I Simpósio de Cognição e Artes Musicais. Curitiba: UFPR, 2005. p. 10-16.

BROWMAN, C. e GOLDSTEIN, L. Dynamics and articulatory phonology. In: PORT, R. e VAN GELDER, T. (Orgs.). Mind as motion. Cambridge: The MIT Press, 1995. p. 175-193.

CHEMERO, A. An outline of a theory of affordances. Ecological Psychology, v. 15.2, p. 181-195, 2003.

CUMMINS, F. Rhythm as entrainment: The case of synchronous speech. Journal of Phonetics, v. 37.1, p. 16-28, 2009a.

p. 15-28, 2009b.

. Rhythm as an affordance for the entrainment of movement. Phonetica, v. 66 (1-2), 
Practice and performance in speech produced synchronously. Journal of Phonetics, v. 31.2, p. 139-148, 2003.

DAUER, R. Stress-timing and syllable timing reanalyzed. Journal of Phonetics, v. 11. p. 51-62, 1983.

GIBSON, J. The ecological approach to visual perception. Dissertação de Mestrado Houghton Mifflin, Boston, 1979.

GOLDSTEIN, L.; BYRD, D.; SALTZMAN, E. The role of vocal tract gestural action units in understanding the evolution of phonology. In: ARBIB, M. From action to language: the mirror neuron system. Cambridge: Cambridge University Press, 2006. p. 215-249.

HAYES, B. Metrical stress theory. Chicago: University of Chicago Press, 1995.

HOCKETT, C. A manual of phonology. In: The origin of speech. Scientific American, Bloomington, v. 203, p. 88-111, 1960.

KRUMHANSL, C. Ritmo e altura na cognição musical. In: ILARI, B. (Org.). Em busca da mente musical: ensaios sobre os processos cognitivos em música - da percepção à produção. Curitiba: Editora UFPR, 2006. p. 45-109.

LARGE, E. e KOLEN, J. Resonance and the perception of musical meter. Connection Science, v. 6, p. 177-208, 1994.

LEHISTE, I. Isochrony reconsidered. Journal of Phonetics, 5, p. 253-263, 1977.

LIBERMAN, M. e PRINCE, A. On stress and linguistic rhythm. Linguistic Inquiry, 8 , p. 249-336, 1977.

Mac WHINNEY, B. Language Emergence. In: BURMEISTER, P.; PISKE, T. and ROHDE, A., (Orgs.). An integrated view of language and development - Papers in honor of Henning Wode. Trier: Wissenshaftliche Verlag, 2002. p. 17-42.

MARTINET, A. Elementos de linguistica geral. 8 ed. São Paulo: Martins Fontes, 1978.

MCAULEY, J. Toward an adaptive oscillator model of rhythm: Technical report 137. Indiana University Cognitive Science Program, Bloomington, Indiana. 1995.

MEDEIROS, B. R. Em busca do som perdido: o que há entre a linguística e a música. In: ILARI, B. (Org.) Em busca da mente musical: ensaios sobre os processos cognitivos em música - da percepção à produção. Curitiba: Editora UFPR, 2006. p. 189-227.

MICHAEL, D. Musical automata as dynamical systems. Adaptive Behaviour, v. 14.2, p. 139-146, 2006.

NOGUEIRA, M. V. O mapeamento da metáfora conceitual e o esquematismo em música. Anais do V Simpósio de Cognição e Artes Musicais. Goiânia: UFG, 2009. p. 154-167.

OLIVEIRA, L. F.; HASELAGER, W.; MANZOLLI, J.; GONZALEZ, M. Significado musical e inferências lógicas a partir da perspectiva do pragmatismo peirceano. Cognição e Artes Musicais, v. 3, p. 67-76, 2008.

OLIVEIRA, F. e RODRIGUES, S. Affordances: a relação entre agente e ambiente. Ciências \& Cognição, v. 9, p. 120-130, 2006. Disponível em: <http: //www.cienciasecongnição.org>.

PIKE, K. The intonation of American English. Ann Arbor: University of Michigan Press, 1945. 
PORT, R. Meter and speech. Journal of Phonetics, 31, p. 599-611, 2003.

PORT, B e VAN GELDER, T. Mind as motion: explorations in the dynamics of cognition. Cambridge: The MIT Press, 1995.

PORT, R., CUMMINS, F. e GASSER, M. A dynamic approach to rhythm in language: toward temporal phonology. Manuscrito inédito. Indiana University. 1995. Disponível em: $<$ http://www.cs.indiana.edu/ p port/>.

PORT, R., CUMMINS, F. e MacAULEY, D. Naive time, temporal patterns and human audition. In: PORT, R. e VAN GELDER, T. (Orgs.). Mind as motion. Cambridge: The MIT Press, 1995. p. 339-371.

RAMUS, F. e MEHLER , J. Language identification with suprasegmental cues: a study based on speech resynthesis. Journal of the Acoustical Society of America, v. 105.1, p. 512-521.

SALTZMAN, E.; NAM, H.; KRIVOKAPIC, J.; GOLDSTEIN, L. A task-dynamic toolkit for modeling the effects of prosodic structures on articulation. Proceedings of Speech Prosody. Campinas: UNCIAMP, 2008.

SCHROEDER, S. Música e linguagem verbal: distanciamentos e aproximações. Anais do / Encontro Nacional de Cognição e Artes Musicais. Curitiba: UFPR, 2006. p. 106-113.

SLOBODA, J. A. A mente musical. Trad. Beatriz Ilari e Rodolfo Ilari. Londrina: Eduel, 2008.

Beatriz Raposo de Medeiros: beatrizrap@gmail.com

Recebido e aprovado em 16 de outubro de 2009 